\title{
Implantação do Programa Saúde na Escola em Fortaleza-CE: atuação de equipe da Estratégia Saúde da Família
}

\author{
School Health Program implementation in Fortaleza-CE: performance of the Family Health Strategy staff \\ Implantación del Programa de Salud Escolar en Fortaleza-CE: desempeño de equipo \\ de la Estrategia Salud de la Familia
}

\begin{abstract}
Lindelvania Matias de Santiago', Malvina Thaís Pacheco Rodrigues", Aldivan Dias de Oliveira Junior'II, Thereza Maria Magalhães Moreira ${ }^{\text {IV }}$
\end{abstract}

'Secretaria Municipal de Saúde de Fortaleza, Estratégia Saúde da Família. Universidade Estadual do Ceará, Grupo de Pesquisa Epidemiologia, Cuidado em Cronicidades e Enfermagem. Fortaleza-CE, Brasil.

"Universidade Estadual do Ceará, Programa de Pós-Graduação em Saúde Coletiva (doutoranda), Grupo de Pesquisa Epidemiologia, Cuidado em Cronicidades e Enfermagem. Fortaleza-CE, Brasil.

"' Secretaria Municipal de Saúde de Fortaleza, Estratégia de Saúde da Família. Fortaleza-CE, Brasil.

"N Universidade Estadual do Ceará, Curso de Graduação em Enfermagem, Mestrado Acadêmico Cuidados Clínicos em Saúde, Mestrado Acadêmico em Saúde Publica e Doutorado em Saúde Coletiva, Grupo de Pesquisa Epidemiologia, Cuidado em Cronicidades e Enfermagem. Pesquisadora do CNPq. Fortaleza-CE, Brasil.

Submissão: 31-10-2010 Aprovação: 04-09-2012

\begin{abstract}
RESUMO
Este trabalho relata a experiência da implantação do Programa Saúde na Escola (PSE) por uma equipe da Estratégia Saúde da Família (ESF) em uma escola pública em Fortaleza-CE. As atividades desenvolvidas incluíram seminário de implantação do PSE com os docentes e integrantes da ESF, oficinas com os estudantes, avaliação clinica e odontológica dos adolescentes e entrega de Cadernetas de Saúde do Adolescente. A implantação do PSE permitiu aos profissionais de saúde a percepção do seu papel social de educador e possibilitou aos adolescentes maior contato com a equipe da ESF. A aproximação entre escola e ESF é fundamental para ajudar os adolescentes a transformarem a informação científica em comportamentos saudáveis.

Descritores: Saúde; Promoção da Saúde; Educação; Saúde Escolar.
\end{abstract}

\section{ABSTRACT}

This work reports the experience of implementation of the School Health Program (PSE) by a team from the Family Health Strategy (FHS) in a public school in Fortaleza-CE, Brazil. The activities included conference about the deployment of the PSE with teachers and members of the FHS, workshops with students, clinical and dental assessment for adolescents and delivery of Booklets of Adolescent Health. The implementation of the PSE allowed health professionals to perceive their social role as educators and provided adolescents a greater contact with the staff from FHS. The rapprochement between the school and the FHS is crucial to help teenagers to transform scientific knowledge into healthy behaviors.

Key words: Health; Health promotion; Education; School Health.

\section{RESUMEN}

Este artículo relata la experiencia de implementación del Programa de Salud Escolar (PSE) por un equipo de la Estrategia de Salud de la Familia (ESF) en una escuela pública en Fortaleza-CE, Brasil. Las actividades incluyeron seminario de despliegue del PSE con los maestros y los miembros de la ESF, talleres con los estudiantes, la evaluación clínica y dental de los adolescentes y la entrega de folletos de Salud del Adolescente. La aplicación del PSE permitió a los profesionales de salud a darse cuenta de su papel social como educadores y permitió a los adolescentes un mayor contacto con el personal de la ESF. El acercamiento entre la escuela y el FSE es crucial para ayudar a los adolescentes a transformar el conocimiento científico en comportamientos saludables. Palabras clave: Salud; Promoción de la Salud; Educación; Salud Escolar. 


\section{INTRODUÇÃO}

O atendimento em saúde, não raro, é desenvolvido em centros de saúde e hospitais. Tal situação distancia a promoção da saúde e prevenção das doenças do contexto comunitário, minimizando o êxito das ações desenvolvidas na atenção primária, sobretudo as relativas a questões socioculturais e psicológicas individuais e comunitárias.

É fundamental que o atendimento à saúde ultrapasse os muros dos hospitais e centros de saúde e envolva a participação de outros setores da sociedade. Para tal, a Estratégia Saúde da Família (ESF) deve buscar continuamente a integração com instituições e organizações sociais por meio de parcerias e deve também realizar diagnóstico situacional para direcionar as atividades prioritárias identificadas. Estas ações devem ocorrer de forma pactuada com a comunidade e serem pautadas em uma postura ativa de colaboração, buscando o cuidado individual e familiar ${ }^{(1-2)}$.

Surge, assim, a importância de conhecer outros dispositivos sociais que contribuam para a promoção da saúde e que possam efetivamente atender às necessidades de saúde dos indivíduos. Nesse contexto, está a escola, que pode se tornar importante aliada para o fortalecimento da atenção primária de saúde.

A escola é formadora de opiniões de crianças, adolescentes e de suas famílias, sendo um dispositivo social a ser utilizado como cenário e ferramenta da educação em saúde, buscando formar cidadãos conscientes e responsáveis por suas escolhas e comportamentos ${ }^{(3)}$.

Neste sentido, o elo saúde e educação é fundamental para alcançar grupos populacionais de crianças e adolescentes.

Destacam-se os adolescentes por ser um grupo que dificilmente comparece aos serviços de saúde e que precisa ser alvo da atenção dos profissionais de saúde.

Para regulamentar as atividades para a saúde no âmbito escolar, o Decreto $\mathrm{n}^{\circ} 6.286$ de 05 de dezembro de $2007^{(4)}$ instituiu o Programa Saúde na Escola (PSE) e suas finalidades; e a Portaria $\mathrm{n}^{\circ} 1.861$, de 04 de setembro de $2008^{(5)}$ regulamentou a responsabilidade orçamentária do Ministério da Saúde (MS) com os municípios que aderem ao PSE.

O PSE é resultado de uma parceria entre os Ministérios da Saúde e Educação e tem como objetivos promover a saúde e a cultura da paz, enfatizando a prevenção de agravos à saúde; articular ações do setor da saúde e da educação, aproveitando o espaço escolar e seus recursos; fortalecer o enfrentamento das vulnerabilidades desta clientela; e incentivar a participação comunitária contribuindo para a formação integral dos estudantes da rede básica ${ }^{(3,6-7)}$.

Neste sentido, o PSE constitui uma possibilidade de suprimento de uma necessidade há tempos discutida: o fortalecimento da integração entre os setores educação e saúde, promovendo a intersetorialidade apregoada pelo Sistema Único de Saúde (SUS) e a corresponsabilização entre estes setores, habituados a trabalhar isoladamente.

A pesquisa tem como objetivo relatar a experiência da implantação do PSE por uma equipe da ESF em uma Escola de Ensino Fundamental e Médio da Rede Estadual de Fortaleza realizada em abril e maio de 2010.

\section{IMPLANTAÇÃO E DESENVOLVIMENTO DO PROGRAMA SAÚDE NA ESCOLA}

A escola na qual foi implantado o PSE tem cerca de mil crianças e adolescentes matriculados. O público alvo inicial do PSE foi de cem adolescentes que integram o Programa Mais Educação, tendo sido cinquenta os participantes diretos das atividades.

Vale salientar que os estudantes que integram o programa Mais Educação permanecem na escola o horário padrão da matriz curricular e o outro turno desenvolvendo atividades extracurriculares.

Em um primeiro momento, as Secretarias Municipais de Saúde e de Educação promoveram um seminário para expor a finalidade do PSE e sua operacionalização, enfocando a importância da parceria entre escola, professores, coordenadores e a ESF para o êxito do programa. Foram convocados para o seminário representantes das escolas a serem beneficiadas com a implantação do PSE e os integrantes da ESF das respectivas áreas de abrangência.

Para operacionalização do desenvolvimento do trabalho, inicialmente a equipe da ESF estabeleceu um vínculo direto com a coordenação da escola, objetivando a integração entre os membros da escola e da ESF. A partir do contato inicial foram agendados encontros para a efetivação das ações.

Antecedendo as atividades com os estudantes, foi realizada uma roda de conversa na escola com os professores e profissionais de saúde, para conhecer a escola, esclarecer dúvidas sobre o programa, e, principalmente, para estabelecer parceria e compromisso entre profissionais de saúde e docentes. Observamos nos encontros com os professores, sua sensibilidade e conhecimento dos problemas hebiátricos, o que os fez, de imediato, colaboradores da ESF para o desenvolvimento das ações propostas. No entanto, os professores e a ESF, apresentavam-se ansiosos acerca da possibilidade de não cumprimento das ações programadas, devido ao acúmulo de tarefas rotineiras.

O objetivo da oficina educativa realizada com os adolescentes foi abordar o funcionamento do PSE. As etapas desta atividade foram: 1) Acolhimento: apresentação e integração do grupo em dinâmica; 2) Conhecendo o programa: exposição de slides sobre o funcionamento e o público-alvo do programa; 3) Discussão dos temas das atividades de educação em saúde com os estudantes; e 4) Avaliação em roda: os participantes sintetizaram em uma palavra o que acharam do evento.

As etapas 1 e 2 foram rápidas. Já na etapa 3, os adolescentes foram convidados a expor, em papel madeira, o que desejavam que fosse abordado nos próximos encontros nas atividades educativas. Na ocasião, os adolescentes foram divididos em três grupos e apresentaram suas demandas.

É primordial que os adolescentes participem da construção dos assuntos a serem abordados, pois uma aprendizagem significativa está relacionada às suas necessidades e vivências. Fomentamos, assim, uma política transversal, construção coletiva e humanizada dos diversos serviços oferecidos nas práticas de saúde, valorizando a corresponsabilidade dos inúmeros atores envolvidos na produção de saúde, estimulando os usuários a participarem efetivamente na construção de saberes ${ }^{(8)}$. 
Os temas mais solicitados foram drogas, gravidez na adolescência, escolha de profissões, doenças sexualmente transmissíveis (DST), violência e direitos dos adolescentes. Observa-se que os temas de interesses dos estudantes são semelhantes aos temas de interesse para a maioria dos outros adolescentes brasileiros. Em um estudo realizado em Araraquara (SP) foi aplicado um questionário a 244 adolescentes de uma escola particular com o objetivo de avaliar a opinião desta clientela a respeito de assuntos importantes relacionados à saúde. Entre os mais relatados foram alimentação saudável, prática de esportes, Síndrome da Imunodeficiência Adquirida (AIDS) e gravidez $^{(9)}$.

Na etapa 4, o evento foi considerado bom, proveitoso, legal e interessante.

Após o encontro inicial, todos os estudantes passaram por avaliação clínica realizada pela enfermeira, médica e odontólogo. As consultas foram realizadas nas dependências da escola. Os achados clínicos, odontológico e dados antropométricos foram registrados em prontuário individualizado. Foram entregues Cadernetas de Saúde do Adolescente. A partir das demandas levantadas, alguns estudantes foram encaminhados para dar continuidade ao tratamento prescrito durante as avaliações. Duas adolescentes foram encaminhadas para acompanhamento com terapeuta ocupacional e psicóloga.

Dando continuidade ao desenvolvimento do PSE, em outro momento, foi desenvolvida uma atividade educativa abordando sexualidade na adolescência, enfocando as mudanças corporais, gravidez, aborto e métodos contraceptivos. Em um trabalho direcionado aos adolescentes de uma escola pública realizado na cidade de Manacapuru-Amazonas, as atividades educativas mostram-se essenciais à reflexão e sensibilização de comportamentos saudáveis pela clientela participante ${ }^{(10)}$.

Os adolescentes apresentaram-se mais interessados quando o assunto abordado foi sexualidade e gravidez na adolescência. Na ocasião uma aluna relatou sua história de vida ao ter engravidado aos 14 anos. A adolescente falou sobre os problemas e dificuldades enfrentados com a gestação precoce, o fato de ter abandonado a escola e o retorno somente após três anos para concluir seus estudos. Foi um momento extremamente rico, de compartilhamento de vivências e opiniões onde os estudantes foram levados a assumir uma postura crítico-reflexiva a partir do diálogo e da problematização, tendo como eixo o pensamento de Paulo Freire ${ }^{(11)}$.

Destacamos que a partir destes encontros os adolescentes se aproximaram da ESF e passaram a comparecer ao serviço de saúde.

Uma das preocupações do grupo de profissionais foi a vinculação das atividades desenvolvidas a um processo educativo emancipatório, destituído da mera repetição de conceitos de saúde na escola. O conhecimento construído ou reformulado foi uma construção coletiva e os autores envolvidos cresceram em conhecimento, revelando-se numa experiência muito rica para os profissionais de saúde.

\section{CONCLUSÃO}

A relação entre os adolescentes e os profissionais de saúde ainda é limitada, sendo a proposta do PSE uma oportunidade para estabelecer e manter um vínculo pautado na co-responsabilização e em uma postura de confiança entre adolescentes e ESF.

A implantação do PSE permitiu aos profissionais de saúde a percepção do seu papel social de educador e possibilitou aos adolescentes maior contato com a equipe da ESF. Consideramos que a aproximação entre escola e unidade de saúde contribuiu para ajudar os adolescentes a transformarem a informação científica em comportamentos saudáveis.

Compreendemos a partir da experiência vivenciada que diversificar os locais de atendimento à saúde, bem como colocar em prática estratégias educativas que vão além das meras palestras tradicionais, ampliam as possibilidades de melhoria da assistência prestada pela equipe da ESF, além de dar maior visibilidade às atividades desenvolvidas na atenção primária.

\section{REFERÊNCIAS}

1. Ministério da Saúde, Secretaria de Atenção á Saúde, Departamento de Atenção Básica. Política nacional de atenção básica. Secretaria de Atenção à Saúde, Departamento de Atenção à Saúde. Brasília: Ministério da Saúde; 2006.

2. Ciampone $\mathbf{M H}$, Peduzzi M. Planejamento Estratégico como Instrumento de Gestão e Assistência. In: Manual de Enfermagem; Instituto para o desenvolvimento da Saúde; Universidade de São Paulo. Brasília: Ministério da Saúde; 2001.

3. Ministério da Saúde, Secretaria de Atenção à Saúde, Departamento de Atenção Básica. Saúde na Escola. Brasília: Ministério da Saúde; 2009.
4. Brasil. Decreto $n^{\circ}$. 6.286, de 5 de dezembro de 2007. Institui o Programa Saúde na Escola - PSE, e dá outras providências. Diário Oficial da união 6 dez 2007.

5. Ministério da Saúde (Brasil). Portaria $n^{\circ} 1.861$ de 4 de setembro de 2008 - estabelece recursos financeiros pela adesão ao PSE para Municípios com equipes de Saúde da Família, priorizados a partir do Índice de Desenvolvimento da Educação Básica - IDEB, que aderirem ao Programa Saúde na Escola-PSE. Diário Oficial da União 5 set 2008.

6. Ministério da Saúde, Ministério da Educação. Programa Saúde na Escola. Brasília: Ministério da Saúde; 2008.

7. Ministério da Saúde. Informe da Atenção Básica. Brasília: 
Ministério da Saúde; 2009.

8. Ministério da Saúde, Núcleo Técnico da Política Nacional de Humanização. HumanizaSus: Política Nacional de Humanização: a humanização como eixo norteador das práticas de atenção e gestão em todas as instâncias do SUS. Brasília: Ministério da Saúde; 2004.

9. Campos JADB, Zuanon, ACC. Educação em saúde: aspectos relevantes apontados por adolescentes. Ciênc Odontol Bras 2004;7(2):55-60.

10. Oliveira HM, Gonçalves MJF. Educação em Saúde: uma experiência transformadora. Rev Bras Enferm 2004;57(6):761-3.

11. Freire P. Pedagogia da Autonomia: saberes necessários à prática educativa. 19. ed. São Paulo: Paz e Terra; 1996. 